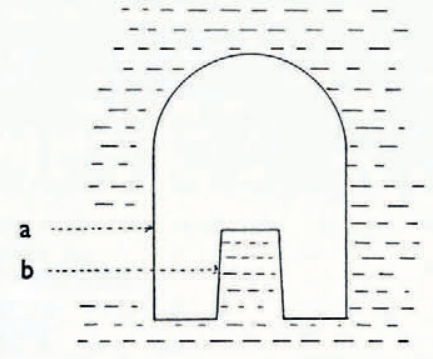

Fig. I. Section through a tunnel near its end. (a) Tunnel wall. (b) Central table

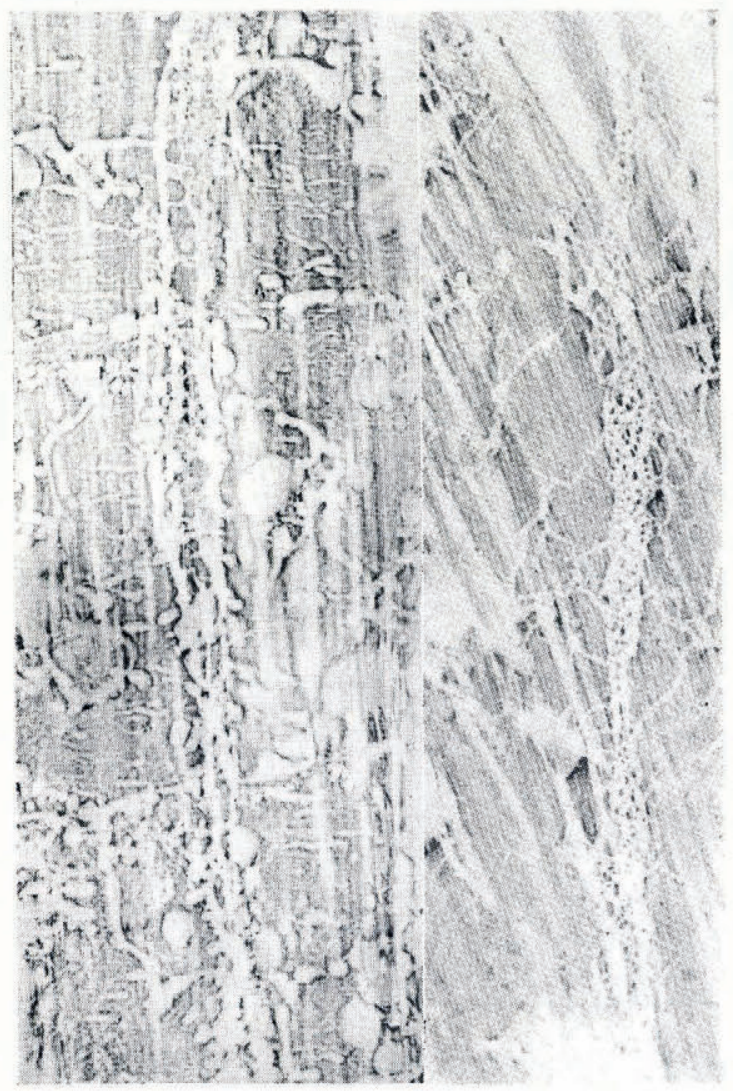

Fig. 3. Rubbings of two horizontal shear planes, natural size. See text p. 381

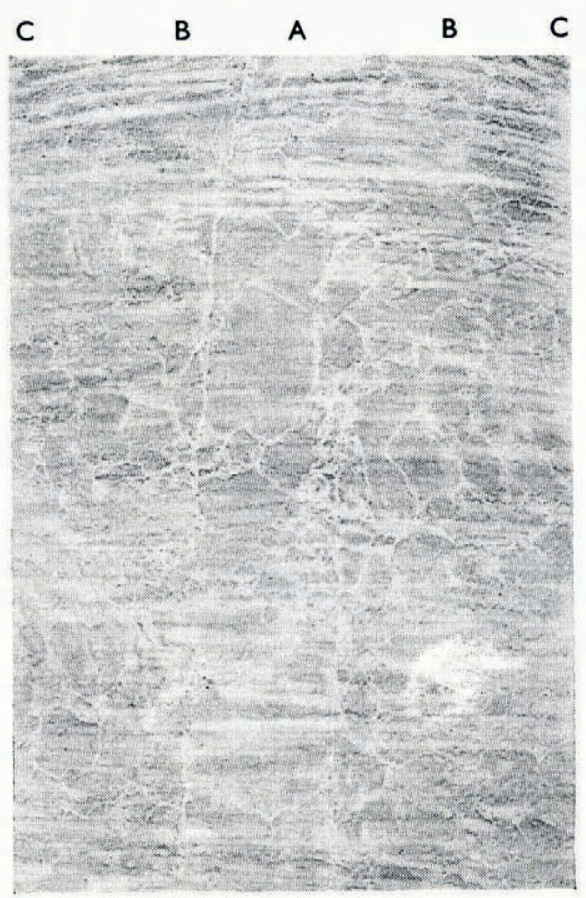

Fig. 2. Rubbing of a vertical blue band in the Bas Glacier d'Arolla, half natural size. See text p. $3^{8 I}$

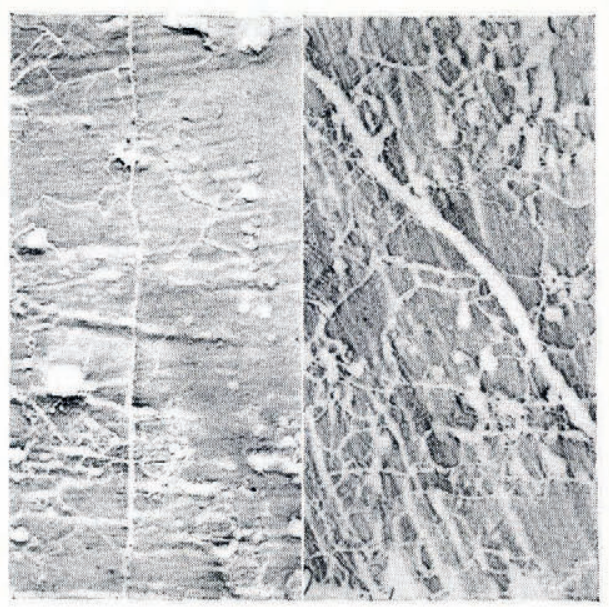

Fig. 4. Two rubbings showing cracks passing through crystals, half natural size 


\title{
THE GROWTH OF THE GLACIER CRYSTAL
}

\section{SOME FURTHER NOTES}

\author{
By Gerald Seligman
}

\section{The Relative Sizes of Crystals on the Glacier Surface and in its Interior}

\section{Z'Mutt Glacier, Zermatt}

In the main paper on this subject ${ }^{1}$ attention was drawn to the fact that the results published applied only "to those parts of a glacier readily accessible" and that "little is known of the crystal conditions deep in glaciers."

Professor A. Renaud, with whom the author was able to discuss this question during investigations on the Z'Mutt Glacier (Zermatt) in July 1949, has pointed out that the crystals on the external skin of the glacier tongue grow to larger size than those deep down in the ice, ${ }^{*}$ owing, he believes, to their having been subjected to higher temperatures. Facilities for putting this point to the test were afforded us in a long tunnel excavated nearly horizontally up-stream in this glacier in connexion with hydro-electric operations.

The root mean square diameter of typical crystals inside the tunnel, $44 \mathrm{~m}$. from its mouth, was $1.7 \mathrm{~cm}$. $\dagger$ while $8 \mathrm{~m}$. vertically above this point on the glacier surface the typical size was $2.2 \mathrm{~cm}$., an increase of nearly 30 per cent. Similar measurements inside the tunnel of the Upper Grindelwald Glacier and ${ }_{5} \mathrm{~m}$. above it on the glacier surface showed an increase of 26 per cent.

Further reference to this point need not be made here since Professor Renaud proposes to handle it in detail.

The author acknowledges the courtesy of S.A. L'Énergie de l'Oueste-Suisse (EOS) of Lausanne in permitting him and a party of colleagues to enter the kilometre-long tunnel to a distance of some $650 \mathrm{~m}$., where many interesting observations were made deep below the glacier surface. He also thanks Professors Renaud_and Haefeli, who made arrangements for their visit.

\section{Sub-normal Crystals in Glaciers}

\section{Upper Grindelwald Glacier}

Reference was made in the same paper (p. 26r) to crystals in the tunnel in the ice fall of the Upper Grindelwald Glacier much smaller in size than might have been expected from measurements made in other glaciers.

The findings referred to in Section I might lead one to think that the tunnel merely opened up the interior of the glacier where smaller crystals were the rule-an explanation mentioned as possible in the main paper but at the time thought to be unlikely by the author, who still believes this to be the case.

The ice fall descends with a circular sweep like a spiral staircase, the true right (outer) margin being less steep than the (inner) left. Therefore if the strains resulting from the stresses set up by the ice fall were the cause of the crystals being smaller owing to recrystallization as was suggested in the paper (p. 264), it would be expected that these stresses and strains would be less severe on the outer margin and the crystals larger. Several attempts at different seasons to climb up and measure the ice crystals in the outer margin to test this view failed owing to falling ice blocks in summer and to iced rocks in winter, but in 1949 a tunnel for tourists was excavated in the outer margin and made accessible by wood steps fixed to the sheer limestone face bordering the glacier.

\footnotetext{
* Professor Ahlmann states he has long believed this to be the case.

$\dagger$ For method of expressing mean crystal sizes see p. 256 of Ref. I below.
} 
The crystals in another tunnel excavated in the spring of 1948 in the inner margin were examined in March 1949; those in the new tunnel on the outer margin in August 1949. Typical samples were found to have a mean crystal diameter of about $0.7 \mathrm{~cm}$. in the tunnel on the inner margin and $0.9 \mathrm{~cm}$. in the tunnel on the outer margin. This gives cause for belief that the higher stresses and the greater strains resulting therefrom in the steeper side of the fall have some connexion with the smaller crystal size.

There is another factor pointing more definitely to the same conclusion. In excavating these tunnels it is the custom to leave standing for decoration at the far end a tabular block of the living ice a metre high and one-half to three-quarters of a metre in length and width (see Fig. I, p. 378). The pressure of the overlying ice is thus removed from this table. The crystals on the surface of these blocks have been measured in three tunnels, two in the right and left margins respectively of the Upper Grindelwald Glacier and one in the Lower Glacier. The latter tunnel was also excavated in an ice fall, although not as steep a one as that on the Upper Glacier. The measurements are given in Table I together with the crystal sizes in the walls of the tunnels nearby.

TABLE I

\begin{tabular}{|c|c|c|c|c|c|c|}
\hline & \multicolumn{2}{|c|}{$\begin{array}{c}\text { Upper Glacier tunnel } \\
\text { in left bank }\end{array}$} & \multicolumn{2}{|c|}{$\begin{array}{l}\text { Upper Glacier tunnel } \\
\text { in right bank }\end{array}$} & \multicolumn{2}{|c|}{ Lower Glacier tunnel } \\
\hline & Central table & $\begin{array}{l}\text { Tunnel wall } \\
\text { nearby }\end{array}$ & Central table & $\begin{array}{l}\text { Tunnel wall } \\
\text { nearby }\end{array}$ & Central table & $\begin{array}{l}\text { Tunnel wall } \\
\text { nearby }\end{array}$ \\
\hline $\begin{array}{l}\text { Mean crystal diameter } \\
\text { Area of largest crystal }\end{array}$ & $\begin{array}{l}\mathrm{x} \cdot 67 \mathrm{~cm} \\
24.0 \mathrm{~cm}^{2}\end{array}$ & $\begin{array}{l}0.75 \mathrm{~cm} \\
3.3 \mathrm{~cm} .^{2}\end{array}$ & $\begin{array}{c}1.52 \mathrm{~cm} \\
40.0 \mathrm{~cm} .^{2}\end{array}$ & $\begin{array}{l}0.88 \mathrm{~cm} . \\
5.2 \quad \mathrm{~cm} .^{2}\end{array}$ & $\begin{array}{l}\mathrm{I} \cdot 75 \mathrm{~cm} \\
7 \cdot 0 \mathrm{~cm} \cdot{ }^{2 *}\end{array}$ & $\begin{array}{l}0.71 \mathrm{~cm} . \\
4.9 \mathrm{~cm} .^{2}\end{array}$ \\
\hline
\end{tabular}

It is very striking that in all cases the mean crystal diameters on the table surfaces $†$ have increased by about roo per cent once they have been fashioned. In the Upper Glacier the largest crystals have a surface area eight times as big as the largest in the tunnel walls nearby. The table was fashioned some nine weeks before these measurements were made, so the growth must have been very quick.

Similar rapid growth was observed in 1947 in two re-entrant angles in a chamber which enlarged the then tunnel (since melted away). Their significance, not then understood, now becomes clear. The mean crystal size was $r .6 \mathrm{~cm}$. as opposed to $0.59 \mathrm{~cm}$. nearby, the respective sizes being shown in the photograph in Fig. 13, p. 267, of the main paper. The overlying pressure on these re-entrant angles would in any case be less tha: that in the neighbouring walls, but in this case, in addition, their upper portion had been partly cut away, further relieving pressure.

A third case of rapid growth was also noted. This was found in certain parts of the roofs of these tunnels. In this case the radial stresses caused by the weight of the overlying ice a few metres above the tunnel roof doubtless undergo a change as they approach the roof. It will be seen that in all these cases the stresses present have either been removed or altered.

This evidence seems to be in accord with laboratory experiments conducted by Hess, ${ }^{2}$ Tammann ${ }^{3}$ and Bader ${ }^{4}$ showing rapid growth of ice crystals after the release of stresses.

The only factor one can adduce for the presence of abnormally small crystals seems to be stress and the strain resulting therefrom and the only cause of stress greater than normal must be the nearness of the ice fall.

\footnotetext{
* In this case no very large crystals were observed; on the other hand all the crystals in the sample were practically uniformly large.

+ It was not possible for the writer to examine the ice in the interior of a table during the tourist season for obvious reasons, but some very indistinct rubbings of these sent to him later do not seem to show much difference between exterior and interior crystal size.
} 
Against this view it could be argued that better circulation of air round the tables might favour rapid growth, as Professor Renaud believes. This might certainly be a factor in the case of the roofs towards which warm air would tend to rise. Nevertheless there can be very little warm air in these ice tunnels. Moreover no large crystals were observed in ice pillars or buttresses or other places well exposed to air circulation but at the same time subjected to pressure from overlying ice.

Further observations are necessary before final conclusions can be drawn. This interim report is published in the hope of drawing attention to these points and of encouraging similar observations to be made elsewhere.

\section{Crystal Size in Blue Bands}

\section{Valais and Bernese Oberland Glaciers}

Varying opinions have been expressed as to the size of crystals in glacier blue bands. Phillip and the majority of authorities have described them as being much smaller than those of the adjacent unbanded ice. Emden has stated the reverse. The author and his colleagues at the Jungfraujoch in 1938 found many bands in the tongue of the Eiger Glacier supporting the latter view.

In 1949 rubbings were made of a number of blue bands in the Arolla, Z'mutt and the two Grindelwald Glaciers.

Fig. 2 (p. 378) shows a rubbing of a $7 \mathrm{~cm}$. wide vertical blue band in the mouth of an artificial tunnel in the Bas Glacier d'Arolla (Valais). There appears to be a sharply defined central zone (A) $2-3 \mathrm{~cm}$. wide containing for the most part large crystals. On both sides of these there are zones $(\mathrm{B}, \mathrm{B})$ containing crystals smaller than in the central zone but larger than in the adjacent ice outside the band $(\mathrm{C}, \mathrm{C})$.

Fig. 3 (p. 378) shows two rubbings, one from the ice fall in the Lower and one from that in the Upper Glacier at Grindelwald. These show what appear to be shear planes, along which are ranged a series of very small crystals which have the appearance of having been ruptured under stress or which might conceivably be early stages in the progress of recrystallization.

It would be interesting, from many points of view, and especially valuable in connexion with the problem of glacier flow, to know whether this denotes an early stage of the large blue band of the type seen in Fig. 2.

The illustrations in Figs. 2 and 3 show the value of the "rubbing" system as an approach to the investigation of possible small scale movements in the glacier.

\section{Cracks through Crystals}

It has always been believed that any cracks or incipient crevasses in glacier ice take place irrespective of the crystal boundaries. Fig. 4 (p. 378 ) is the first corroborative evidence of this that the writer has seen. It shows a number of horizontal shear planes and a vertical crack (without displacement) which clearly passes through the centre of a number of crystals.

These investigations were largely financed by grants from the Royal Society.

\section{R E F E R E N C E S}

1. Seligman, Gerald. Fournal of Glaciology, Vol. I, No. 5, 1949, p. 254-67.

2. Hess, Hans. Die Gletscher. Braunschweig: 1904, p. 31-33.

3. Tammann, G. and Dreyer, K. L. Die Rekristallisation leicht schmelzender Stoffe und die des Eises. Zeitschrift für anorgan. und allgemeine Chemie, Bd. 183 , 1929, p. 289-313.

4. Bader, H. and others. Der Schnee und seine Metamorphose. Beiträge zur Geologie der Schweiz, Geotechnische Serie Hydrologie, Lieferung 3. Kümmerly und Frey: Bern, 1939, p. 45-6r. 